\section{La Révolution française}

Cahiers de l'Institut d'histoire de la Révolution française

9| 2015

Citoyenneté, république, démocratie dans la France de la Révolution

\title{
La citoyenneté revisitée : bilans et perspectives historiographiques
}

\section{Virginie Martin}

\section{(2) OpenEdition}

\section{Journals}

Édition électronique

URL : http://journals.openedition.org/lrf/1370

DOI : $10.4000 /$ Irf. 1370

ISSN : 2105-2557

Éditeur

IHMC - Institut d'histoire moderne et contemporaine (UMR 8066)

Référence électronique

Virginie Martin, «La citoyenneté revisitée : bilans et perspectives historiographiques », La Révolution française [En ligne], 9 | 2015, mis en ligne le 16 novembre 2015, consulté le 02 mai 2019. URL : http:// journals.openedition.org/Irf/1370 ; DOI : 10.4000/Irf.1370

Ce document a été généré automatiquement le 2 mai 2019.

(c) La Révolution française 


\title{
La citoyenneté revisitée : bilans et perspectives historiographiques
}

\author{
Virginie Martin
}

1 En 1988, Michel Vovelle écrivait au sujet de l'historiographie de la Révolution: «On ne saurait plus désormais parler d'une lecture hégémonique en ce domaine, marqué par une explosion tous azimuts, et c'est sans doute un bien ${ }^{1}$." Cinq ans plus tard, il n'y a en revanche plus de doute possible. C'est désormais sans aucune réserve que le même historien affirme : «Il n'y a plus aujourd'hui de discours hégémonique sur la Révolution et c'est un bien ${ }^{2}$. " En effet, entre temps, le Bicentenaire a sonné le glas de ce discours qui fut prédominant des années 1920 jusque dans les années 1980 dans l'historiographie dite «jacobine » ou « classique ", même s'il était déjà fortement contesté depuis les années 1960 par l'historiographie dite «critique » ou « révisionniste. » Ce discours, enterré en 1989 au terme de cette « guerre de tranchée ${ }^{3}$ » qui opposa pendant plus de vingt ans les deux camps historiographiques, c'est celui qui consistait principalement à interpréter les dynamiques politiques en termes d'affrontements de classes sociales.

2 La déconstruction de ce paradigme a eu essentiellement deux conséquences : elle a d'abord permis aux historiens de la Révolution, à rebours des champs balisés et des concepts banalisés de l'histoire sociale, de renouveler leurs méthodes, de diversifier leurs objets et, donc, de complexifier leurs interprétations - au risque d'une dispersion, voire d'un éparpillement des discours qui irait jusqu'à menacer la cohérence d'ensemble de la période ${ }^{4}$. C'est sans doute cette quête d'intelligibilité inédite qui explique que, depuis vingt-cinq ans, les publications exclusivement consacrées à l'historiographie de la Révolution se soient multipliées dans des proportions assez déconcertantes. On en dénombre en effet près d'une dizaine visant à rendre compte des bouleversements et des renouvellements historiographiques induits par le séisme herméneutique du Bicentenaire - sous la forme soit de «bilans » à chaud, soit de présentations des « chantiers » en cours ${ }^{5}$ .Ce faisant, il s'agit donc de rendre visible une période qui, depuis qu'elle ne jouit plus du rayonnement médiatique du Bicentenaire, souffre moins d'une éclipse que d'un discrédit tenace. Mais il s'agit aussi de rendre lisible une histoire « déboussolée » qui, parce qu'elle 
ne bénéficie plus d'aucun grand récit canonique ${ }^{6}$, ni d'aucune grille explicative préétablie, est désormais en quête de repères. Si cette obsession de l'inventaire procède donc à l'évidence d'une volonté de mise au point et de mise en ordre des différents champs explorés depuis le Bicentenaire, tant par l'historiographie française qu'anglo-saxonne ${ }^{7}$, elle trahit aussi le besoin, à peine déguisé, de témoigner à la fois de la vitalité, de la fécondité et même de l'actualité d'une histoire que, quarante ans plus tôt, François Furet avait souhaité "terminer ${ }^{8}$ ", et qui serait aujourd'hui en passe d'être «enterrée ${ }^{9}$.» Les titres de ces synthèses historiographiques sont à cet égard éloquents : en 2001, sous la direction de Martine Lapied et Christine Peyrard, l'histoire de la Révolution se veut au " carrefour des recherches ${ }^{10}$ "; en 2005, sous la direction de Jean-Clément Martin, elle est encore « à l'œuvre ${ }^{11}$ »; en 2010 enfin, sous la direction de Michel Biard, elle se revendique comme «toujours vivante ${ }^{12}$.» Ces titres témoignent à l'évidence d'une posture résolument militante, qui consiste à refuser la liquidation sans procès de cette histoire qui était déjà dans les années 1990 accusée d'être sclérosée ${ }^{13}$ et qui est désormais suspectée d'être dépassée. Ces inventaires en marche participent donc d'une volonté manifeste de défendre, tant dans sa complexité scientifique que dans son actualité politique, une histoire qui, si elle ne bénéficie plus ni des faveurs, ni des certitudes d'antan, est toutefois moins anachronique et moribonde qu'il y paraît ${ }^{14}$.

Cette remise en cause de l'histoire sociale a également eu pour conséquence la remise à l'honneur de l'histoire politique, diagnostiquée dès 1997 par Michel Vovelle en termes de glissement du «tout social » au " tout politique ${ }^{15}$. " Ce n'est d'ailleurs pas un hasard si ce « retour du politique» a été placé sous les auspices d'un «revenant» qui fut l'un des grands vaincus de l'histoire sociale dans les années 1920 et l'un des premiers pionniers de l'histoire républicaine de la Révolution dans les années 1880 : l'historien Alphonse Aulard ${ }^{16}$. Surtout retenu comme le premier titulaire de la chaire d'Histoire de la Révolution française à la Sorbonne en 1885 et comme la cheville ouvrière du Centenaire de 1889, Aulard est aussi l'auteur, en 1901, d'une Histoire politique de la Révolution ${ }^{17}$, dont le soustitre "L'origine et le développement de la Démocratie et de la République» dit assez la perspective dans laquelle il l'étudiait. Si cette perspective n'a pas fait florès dans le champ des études révolutionnaires, c'est parce qu'elle a été férocement battue en brèche, et même battue tout court, dès les années 1920 par l'histoire sociale initiée par son élève, Albert Mathiez. Si le Bicentenaire peut donc être considéré comme une sorte de "revanche aulardienne", c'est seulement au sens où, désormais, l'histoire de la République et de la démocratie, dont Aulard avait été le précurseur, constitue désormais l'un des chantiers privilégiés de l'histoire politique de la Révolution.

Plus qu'un "retour du politique " aux allures de "revanche aulardienne », c'est plutôt une autre manière de faire et d'écrire l'histoire du politique qui s'est imposée depuis une trentaine d'années. Cette autre histoire du politique ne s'est pourtant pas seulement caractérisée par la diversification de ses objets et de ses outils d'analyse - saluée par JeanClément Martin en termes de "décentrement des regards" et par Haïm Burstin en termes de "dérégulation des approches. » Elle s'est traduite aussi et surtout par un élargissement de ses échelles, tant géographiques que temporelles. En effet le principal « effet Bicentenaire » a consisté à la fois à sortir l'histoire de la Révolution du pré-carré strictement franco-français dans lequel elle avait été trop longtemps confinée ${ }^{18}$ et, parallèlement, à l'extirper du carcan de la seule décennie révolutionnaire à laquelle elle était encore trop souvent bornée ${ }^{19}$. C'est donc ce double décloisonnement des échelles du politique qui a permis, d'une part, de réintégrer la décennie révolutionnaire dans la 
longue durée du républicanisme français, en jetant des ponts en amont comme en aval avec ses avatars de l'époque moderne et contemporaine afin de redonner à ce premier « moment républicain » sa place matricielle dans la genèse du républicanisme français ${ }^{20}$; d'autre part, d'étudier le phénomène révolutionnaire et le régime républicain non plus comme un monopole hexagonal, mais dans une perspective mondiale, qui a ainsi abouti à une remise en cause du dogme tenace de «l'exception française.» Alors qu'en 1994, le diptyque Révolution-République semblait encore relever de cette " exception française ", lors du colloque éponyme organisé par Michel Vovelle ${ }^{21}$, dix ans plus tard, c'est en tenant compte des renouvellements induits par l'étude des révolutions atlantiques que Annie Jourdan pouvait se permettre de remettre en question la pertinence d'une telle « exception ${ }^{22}$.» Or, c'est précisément parce que cette Révolution ne fait plus figure «d'exception » que, depuis vingt-cinq ans, il est devenu possible de réinterroger la singularité du modèle révolutionnaire français par rapport aux modèles étrangers ${ }^{23}$ (ce qui fit l'objet en 2004 de la question d'agrégation en histoire moderne ${ }^{24}$ ) mais également de repenser le caractère fondateur du modèle républicain qui s'invente sous la Révolution par rapport à tous ceux qui lui ont succédé au XIX ${ }^{e}$ siècle (ce qui a donc justifié sa mise au programme pour la question d'histoire contemporaine en 2014). En conséquence, cette nouvelle histoire du politique a donc conduit à réinterroger parallèlement l'histoire des Républiques et des citoyennetés.

\section{La citoyenneté révolutionnaire : de l'éclipse à l'émergence historiographique d'un sujet neuf}

6 En effet, la déconstruction des catégories consacrées de l'histoire sociale a permis de dégager l'étude de la «démocratie» et de la «République» de la gangue d'une terminologie sinon réductrice, du moins réifiée, qui interdisait d'en faire des sujets d'études à part entière.

\section{Redéfinition des catégories du politique, redécoupage des temps du politique}

7 Une telle déconstruction a en effet amené les historiens à redéfinir scrupuleusement les concepts et les notions qui servaient jusqu'alors à désigner les catégories sociopolitiques convenues - à commencer par celles de «jacobinisme », de "bourgeoisie » et même de « République ».

8 Il est ainsi symptomatique qu'à propos du concept de «jacobinisme », Françoise Brunel avoue en 2002 ne plus « savoir très bien ce que ce terme signifie ${ }^{25}$. " Symptomatique aussi, le fait que les dynamiques sociales sous la Révolution ne soient plus interprétées désormais sous l'angle d'une inéluctable marche vers le triomphe de la bourgeoisie, mais qu'elles soient désormais appréhendées, sous une forme interrogative, sous l'angle de la construction d'un « ordre bourgeois ${ }^{26}$.»

9 En conséquence, c'est l'ensemble de la périodisation canonique communément admise qui a fini par voler en éclats. Celle-ci répondait jusqu'alors à une typologie chronologique bien arrêtée, qui s'articulait soit autour de la tripartition aulardienne entre "république démocratique » (1792-1795), « république bourgeoise » (1795-1799) et «république 
plébiscitaire » (1799-1804), soit autour de l'opposition soboulienne entre, d'un côté, la « démocratie directe » ou « sociale » permise par la « dictature jacobine » de l'an II et, de l'autre, la république bourgeoise du Directoire comme expression achevée de la « révolution bourgeoise » de 1789. Désormais, si la République n'est plus si évidemment «démocratique » et / ou "terroriste » en l'an II, elle n'est plus non plus considérée comme si « réactionnaire » en l'an III et « conservatrice » sous le Directoire - comme l'ont démontré les récents travaux collectifs destinés à cerner l'essence problématique du républicanisme et les formes successives « des Républiques » sous la Révolution ${ }^{27}$.

Il en va de même pour cette monarchie en Révolution communément retenue sous le nom de "monarchie constitutionnelle », qu'Edgar Quinet qualifiait en 1865 de "démocratie royale ${ }^{28}$ ", que Ran Halévi considère quant à lui comme une " monarchie républicaine ${ }^{29}$ " et que Pierre Serna a rebaptisé du nom de "monarchie représentative ${ }^{30}$. " Le fait même que les régimes politiques successifs ne portent plus les étiquettes commodes dont ils ont été si longtemps affublés a donc entraîné un nécessaire redécoupage des temps du politique en fonction de critères différents de ceux généralement retenus pour justifier les ruptures canoniques que l'on sait (depuis celle de 1792 jusqu'à celle de 1799 en passant par celle de 1795) ${ }^{31}$. Ces temps du politique sont désormais autant redéfinis que redécoupés, non plus en fonction des rapports de forces entre les " partis " politiques qui dominent successivement l'Assemblée, mais en fonction des rapports dialectiques qu'entretiennent entre elles les notions de « souveraineté » et de « représentation. » De fait, aujourd'hui, c'est plutôt la genèse problématique et la construction contrariée de la "démocratie représentative " qui est au cœur des recherches et qui a permis, non seulement de réinterroger en termes de «moments » l'éventail « des Républiques » mais également de revisiter l'essence plurielle « des citoyennetés. »

\section{La citoyenneté occultée : les raisons d'une éclipse historiographique durable}

11 Si le thème de la citoyenneté semble a priori un objet historique éminemment classique, c'est pourtant presque un sujet neuf d'un point de vue historiographique. C'est en effet seulement à partir des années 1990 que l'étude de la citoyenneté est en quelque sorte devenue d'actualité, les historiens du politique commençant alors seulement à questionner véritablement ses frontières et sa signification ${ }^{32}$. Ainsi, depuis le début du siècle, ce ne sont pas moins de quatre ouvrages collectifs qui lui ont été consacrés preuve s'il en est que ce sens était encore loin d'être épuisé faute d'avoir été véritablement explorés3.

12 Jusqu'à cette date en effet, le sujet de la "citoyenneté » semble avoir été soigneusement contourné, voire éludé, comme si finalement il allait tellement de soi qu'il ne semblait pas devoir être étudié en tant que tel. Pour preuve, en cent ans de publications (1908-2008), le sommaire des Annales Historiques de la Révolution française ne recense que douze titres d'articles relatifs à cette thématique. De même, dans les deux dictionnaires « canoniques » de la Révolution, si les termes de « République » et « démocratie » ont bel et bien leurs entrées, celui de « citoyenneté " y est en revanche singulièrement absent ${ }^{34}$.

13 En effet, tout se passe comme si la figure cardinale du citoyen n'avait jamais cessé d'être éclipsée par des figures dérivées qui, en en constituant en quelque sorte le synonyme ou, mieux encore, la synecdoque, ont occulté sa singularité. Éclipsée d'abord, tout au long du $\mathrm{XIX}^{\mathrm{e}}$ siècle, par celle, écrasante, du peuple : d'Augustin Thierry à Jean Jaurès en passant 
par Jules Michelet, ce peuple semblait à lui seul absorber l'essence démocratique d'une Révolution qui se résumait alors davantage au poids de la masse qu'à la qualité de citoyen 35. Éclipsée aussi par les grands noms du Panthéon révolutionnaire qui ont tant occupé le devant de la scène politique qu'ils ont fini par reléguer les simples citoyens dans les coulisses de l'historiographie. Éclipsée enfin, au cours du XXe siècle, par la subdivision de la société en "classes", lesquelles tendaient de façon aussi schématique que manichéenne à réduire le citoyen tantôt au sans-culotte démocrate, tantôt au bourgeois conservateur. C'est donc sans doute ce besoin forcené d'incarner la citoyenneté, soit dans une masse populaire indistincte, soit dans une galerie de portraits sélectifs, soit dans les différentes classes de l'histoire sociale, qui a contribué à cet effacement historiographique de la figure du citoyen - lequel n'appelait finalement aucune définition autre que celle des identités éponymes dont il fut successivement revêtu.

Si la citoyenneté a contribué à émerger en tant qu'objet d'études à partir des années 1990, c'est en raison de l'attention inédite portée à cette date, d'une part aux trajectoires individuelles des « acteurs » (qui ont alimenté la production de nombreuses biographies ${ }^{36}$ ) et d'autre part, aux identités plurielles des " groupes » (qui commencèrent à ne plus être envisagés comme les représentants de classes que comme le produit de réseaux ${ }^{37}$. De là, on a fini par s'interroger sur ce qui faisait de cette somme d'individus et de cette collection de groupes une communauté de citoyens - ce que l'on doit d'ailleurs davantage à l'origine aux historiens spécialisés dans l'histoire de la langue et dans l'histoire du droit qu'aux historiens du politique.

\section{La redécouverte de la citoyenneté : une relecture par les mots et par le droit}

15 En effet, la première étape de ce chantier réactualisé de la citoyenneté a porté sur ce qui définit le citoyen - tant en termes sémantiques que juridiques.

À partir des années 1980, ce n'est pas la figure du citoyen qui réapparaît en tant que telle : c'est plutôt le sens même du mot «citoyen " qui est revisité, permettant ce faisant de faire émerger des perspectives neuves dans la conception même de la citoyenneté. Il appartient aux historiens de la langue politique, et tout particulièrement à ceux réunis au sein de l'équipe de lexicologie politique " $18^{\mathrm{e}}$ et Révolution » de l'ENS Saint-Cloud, d'avoir exhumé à la fois la généalogie complexe du terme même de citoyen ainsi que ses usages contradictoires sous la Révolution ${ }^{38}$. Les nombreux articles que Raymonde Monnier, Jacques Guilhaumou et Annie Geffroy ont en effet consacrés aux notions-concepts ${ }^{39}$ de " peuple », « démocratie », « représentation » et " République » ne permettent plus de les considérer comme des catégories politiques réifiées dont le sens aurait été fixé à l'avance et arrêté de façon définitive : ce sens flou et flottant ne cesse en effet de se redéfinir au fil de la construction ou de la réfutation des régimes que ces termes baptisent ${ }^{40}$. En cela, ces historiens ont démontré que c'était d'abord dans la langue que s'inventaient le politique et la citoyennetée ${ }^{41}$.

Mais c'est aussi dans le droit que ce sens se construit, dans la mesure où c'est l'extension plus ou moins grande des droits qui sont reconnus aux citoyens qui révèle à la fois la nature des régimes qui les définissent et la conception même de la démocratie qui les sous-tend. C'est donc logiquement aux historiens du droit qu'il appartient d'avoir exploré ces définitions juridiques de la citoyenneté, sous l'angle du droit civil et du droit pénal avec les travaux de Jean-Louis Halpérin, Michel Borgetto, Pierre Lascoumes, Pierrette 
Poncela et Pierre Lenoël ${ }^{42}$, mais également sous l'angle des droits politiques, via les nombreux travaux que Michel Troper, Michel Pertué, Marcel Morabito et Guillaume Glénard ont consacrés aux différentes constitutions de la période révolutionnaire ${ }^{43}$.

Le dialogue étroit qui s'est noué depuis une vingtaine d'années entre les historiens du droit et les historiens de la Révolution ne relève ainsi pas du hasard: il est bel et bien le symptôme d'une approche renouvelée du politique, qui n'est plus désormais seulement envisagé désormais comme le fruit de luttes partisanes, mais également comme un produit et comme un producteur de droit. C'est ce changement de perspective qui explique le glissement entre une histoire politique qui était encore très « culturelle » dans les années 1990 à une histoire politique beaucoup plus institutionnelle depuis le début du siècle ${ }^{44}$. À travers la prolifération ces dernières années des études portant sur la fabrique de la loi ${ }^{45}$, sur le fonctionnement parlementaire ${ }^{46}$, sur les rouages gouvernementaux ${ }^{47}$, sur l'articulation entre centre/local et périphéries du politique ${ }^{48}$, ce sont désormais les différentes modalités de constructions et de déclinaisons d'un «ordre républicain » qui sont au cœur des interrogations des historiens du politique - que cet ordre soit «légal », " public », " privé », « bourgeois », « biographique », « diplomatique »" ${ }^{49}$, et même, sous la plume d'Isser Woloch, « civique ${ }^{50}$.»

Or, c'est bel et bien parce que l'histoire politique s'intéresse désormais aux formes et aux évolutions de cet Etat de droit que le citoyen a été reconnu et qu'il est désormais étudié comme un sujet de droits. Dans cette perspective, on peut brièvement dégager trois pistes de réflexion qui ont contribué à renouveler de fond en comble les recherches sur la citoyenneté.

\section{Le citoyen comme " sujet de droits »: les renouvellements historiographiques récents}

20 L'intérêt porté au statut du citoyen comme «sujet de droit » a d'abord contribué à réévaluer les pratiques et les espaces à travers lesquels la citoyenneté était jusqu'ici canoniquement étudiée. Désormais, le citoyen est moins appréhendé à l'aune de son engagement révolutionnaire qu'à l'aune de l'exercice des droits qui lui sont reconnus - au premier rang desquels : le droit de suffrage.

\section{Les élections, d'une impasse à un « âge d'or » historiographique : du citoyen-militant au citoyen-votant}

21 Paradoxalement, c'est seulement dans les trente dernières années que le thème des élections s'est véritablement imposé comme l'un des chantiers majeurs des études révolutionnaires, au point qu'en 2002, Malcolm Crook a pu parler d'un véritable «âge d'or ${ }^{51}$ » pour qualifier ce renouveau historiographique. Sans même recenser les innombrables articles produits sur le sujet, ce sont au moins une dizaine d'ouvrages qui, depuis le tournant du siècle dernier, sont venus enrichir la connaissance du fait et des pratiques électorales sous la Révolution et approfondir la notion de "démocratie représentative. " En effet, si l'innovation radicale de la Révolution tient à la transformation du sujet du roi en un "sujet de droit» et à l'invention concomitante de cette forme inédite de démocratie par représentation, le premier des droits politiques du citoyen réside dans ce droit de suffrage, puisque, pour citer encore Malcolm Crook, «ce sont les élections qui 
font le citoyen plutôt que l'inverse ${ }^{52}$.» Cette fortune historiographique est d'autant plus à souligner qu'à la veille du Bicentenaire, François Furet déplorait le fait que ces élections fussent encore le «parent pauvre de l'historiographie de la Révolution ${ }^{53}$.» Trois raisons peuvent être avancées pour expliquer le fait que la thématique électorale ait tant tardé à s'imposer dans le champ historiographique.

Premièrement, les élections de la Révolution ont longtemps été déconsidérées par les historiens contemporanéistes, à commencer par Maurice Agulhon, comme la "préhistoire de la démocratie moderne ${ }^{54}$ ", en raison de leurs innombrables manquements: absence d'individualisation du vote (qui persiste à se faire en assemblées); absence de " campagne » proprement dite (faute de candidats déclarés et de « partis » clairement constitués) ; absence de réelle représentativité (en regard des faibles taux de participation, des forts soupçons de manipulations et d'un suffrage qui demeure censitaire...). À cette disqualification globale qui procède avant tout de la tendance à " plaquer » sur la période révolutionnaire le schéma électoral, sinon "idéal », du moins "abouti", de la démocratie contemporaine, s'ajoute aussi la surfocalisation des contemporanéistes sur un seul type de vote : « le vote de référence » que constituent les élections législatives (qui mobilisèrent peu sous la Révolution), au détriment de deux types d'élections qui connurent bien plus de succès: les élections locales (évacuées comme secondaires) et les votes référendaires directs (dévalués comme des " plébiscites » sans valeur). Notons enfin que ces élections étaient d'autant moins susceptibles d'être explorées qu'elles n'auraient pas généré la documentation archivistique adéquate pour mener à bien des études sérielles. Ce sont les lacunes de ces sources électorales, trop éparses et trop étriquées, qui ont été scrupuleusement recensées dès 1968 par Jean-René Surrateau ${ }^{55}$. Selon Serge Aberdam, si justes que soient ses précautions méthodologiques, elles ont plutôt dissuadé qu'encouragé les chercheurs à se lancer sur ce terrain "glissant » des élections ${ }^{56}$. Par conséquent, alors que, dès 1959, Robert Palmer appelait à rénover le sens même de la démocratie à partir d'études systématiques menées sur les élections ${ }^{57}$, ce défi n'a finalement pas été relevé. Et ce d'autant moins qu'un an plus tôt Albert Soboul imposait un sens de la démocratie univoque en publiant sa thèse sur les sans-culottes parisiens ${ }^{58}$.

En effet, la seconde raison qui a contribué à occulter le champ électoral, c'est le postulat tenace, érigé en véritable dogme par l'histoire sociale, selon lequel l'authentique démocratie, c'était par définition celle "directe " (exercée par le peuple) et non celle "représentative» (confisquée par la bourgeoisie). De ce fait, les recherches se sont essentiellement concentrées sur un seul type d'espaces (l'espace public au détriment de l'espace électoral) et résumées à une seule de ses expressions (celle des sociétés populaires au détriment de celle des assemblées primaires). En résumé, parce que la démocratie se faisait davantage par la voix de la rue que par la voie des urnes, la figure cardinale du citoyen par excellence se confondait moins avec celle du votant que du militant - qu'il soit sectionnaire, jacobin, cordelier, sans-culotte, etc...

La renaissance tardive de l'histoire des élections s'explique donc avant tout par la nécessité de défricher un champ qui avait été jusqu'ici soigneusement tenu à l'écart des sentiers battus de l'histoire sociale. Mais pas seulement. On peut également considérer qu'à partir des années 1990, cette renaissance s'est faite en écho, et peut-être même en réponse, aux thèses développées au sein de l'École des Hautes Etudes en Sciences Sociales par deux historiens: Pierre Rosanvallon, auteur d'une véritable archéologie ${ }^{59}$ de la démocratie française en trois volumes ${ }^{60}$, et Patrice Gueniffey, auteur en 1993 d'une des 
premières thèses sur les élections qui, de manière significative, a pris pour titre l'une des formules de Rosanvallon, Le nombre et la raison ${ }^{61}$. Or, l'un comme l'autre ont contribué à accréditer l'idée d'une sorte d'échec ou du moins d'aporie constitutive de la démocratie représentative sous la Révolution ${ }^{62}$. Qu'elle soit « impossible » pour Pierre Rosanvallon en raison d'un peuple "introuvable », ou bien "inopérante " pour Patrice Gueniffey en raison d'un peuple "manipulable», la démocratie représentative telle qu'elle s'invente (pour Rosanvallon) et qu'elle se pratique (pour Gueniffey) sous la Révolution comportait finalement trop de failles intrinsèques pour permettre aux élections, d'être, en droit et de fait, l'expression authentique du peuple souverain - souverain fantoche dont la voix aurait été confisquée, soit par les représentants élus (pour Rosanvallon), soit par les militants jacobins (pour Gueniffey).

C'est une lecture bien plus nuancée du fait électoral et du concept de "démocratie représentative » qu'ont donc proposés les historiens de la Révolution, à partir notamment des travaux menés dans les années 1990 par l'équipe réunie au sein de l'atelier Voter / Elire sous la houlette de Bernard Gainot, Serge Bianchi et Serge Aberdam ${ }^{63}$. À partir de l'étude empirique des pratiques et des procédures électorales, ces historiens ont en effet permis de réévaluer les enjeux et les effets politiques de cette démocratie représentative par rapport à toutes les autres formes de démocratie dites improprement "directes » qui avaient jusqu'ici confisqué l'attention des historiens du politique ${ }^{64}$. Claudine Wolikow a ainsi montré que la démocratie représentative constituait une alternative au gouvernement représentatif inventé par Sieyès en $1789^{65}$, avant de devenir, sous le Directoire, cette "alternative à Brumaire " pour les néo-jacobins étudiés par Bernard Gainot ${ }^{66}$. De son côté, Serge Aberdam a prouvé que l'institutionnalisation de la démocratie représentative entre 1792 et 1793 avait permis la mise en œuvre d'une véritable "démocratie délibérative ${ }^{67}$ " au sein des assemblées primaires ${ }^{68}$. Ce faisant, non seulement le concept de "démocratie représentative » a constitué, dès l'été 1791 , le principal moteur de l'aspiration républicaine pour tous les détracteurs de la monarchie constitutionnelle, mais il a constitué aussi la clé de voûte de la construction d'une République démocratique à partir de 1792, avant de devenir le fer de lance de la résistance au conservatisme politique et social à partir de 1795 .

Tous ces travaux ont été, entre temps et depuis, complétés et approfondis par les études réalisées par les juristes sur le droit de suffrage (en particulier par Michel Pertué et Philippe Tanchoux ${ }^{69}$ ) ainsi que par ceux réalisés sur les pratiques électorales par les historiens anglo-saxons (notamment par Malcolm Crook $^{70}$ et Melvin Edelstein ${ }^{71}$ ). Si ce dernier a publié en 2014 une volumineuse synthèse de ses trente années de recherche sous le titre La Révolution et la naissance de la démocratie électorale ${ }^{72}$, c'est d'ailleurs dans le but avoué de prouver que les élections de la période révolutionnaire constituent bel et bien «l'une des sources de la démocratie moderne » et pour avoir ainsi le « dernier mot » dans le débat qui l'oppose depuis plus de vingt ans à Patrice Gueniffey ${ }^{73}$.

C'est donc l'ensemble de ces recherches qui a permis non seulement d'affiner les taux de participation mais également de réévaluer les enjeux de cette notion de "démocratie représentative ", à trois titres: d'une part, par rapport aux définitions du droit de suffrage, ces travaux ne permettent plus d'opposer strictement, comme le faisait Alphonse Aulard, le suffrage "censitaire» de 1789 au suffrage "universel» de 1792; d'autre part, par rapport aux taux de participation aux différentes élections, ils ont démontré qu'ils étaient généralement beaucoup moins «faibles » que ce que l'on pouvait en dire; enfin, du point de vue de l'impact des pratiques électorales sur l'acculturation 
politique des masses paysannes, ils ont abouti à la conclusion que celle-ci ne date pas de la III ${ }^{e}$ République, comme le voulait Eugen Weber en $1976^{74}$, ni même de la II ${ }^{e}$ République, comme l'affirmait Maurice Agulhon ${ }^{75}$, mais bel et bien de la décennie révolutionnaire ${ }^{76}$.

En opérant ainsi un déplacement de la focale, depuis le champ largement labouré par l'histoire sociale, de la citoyenneté telle qu'elle s'exprime dans l'espace public jusqu'au champ, largement délaissé, de la citoyenneté telle qu'elle se pratique dans l'espace électoral, c'est bel et bien une autre approche de l'apprentissage de la démocratie qui a donc fini par s'imposer. Ce déplacement de la focale historiographique sur la figure du citoyen-électeur s'est par ailleurs accompagné d'un recentrement des recherches sur les figures des " citoyens-limites ", autrement dit sur les catégories sociales qui se situent à la marge de la citoyenneté, qu'ils soient "non-citoyens" (exclus des droits de citoyenneté) ou " demi-citoyens ${ }^{77}$ » (ne jouissant que d'une partie seulement des droits reconnus aux citoyens).

\section{Un recentrement historiographique sur les frontières de la citoyenneté : les « citoyens-limites »}

Il n'est qu'à s'en tenir aux titres mêmes des ouvrages recensés dans la bibliographie d' Historiens-Géographes pour mesurer l'importance historiographique de ces citoyens-limites qui, pour des raisons de race, de sexe ou de nationalité, ne sont pas citoyens ou pas pleinement citoyens et qui luttent donc pour obtenir, en vertu de leurs droits naturels, des droits civils et/ou politiques. Ainsi, ce sont donc ceux qui se situent à la périphérie de la communauté des citoyens, qui occupent actuellement une place centrale dans les études sur la citoyenneté - trois d'entre eux en particulier : les populations des colonies, les femmes et les étrangers. Tout se passe donc comme si c'était à partir de ces frontières mouvantes de la citoyenneté que l'identité citoyenne avait été réinterrogée - comme si, donc, c'était à partir de la définition «négative » de la citoyenneté qu'il était finalement possible de saisir l'essence même de la citoyenneté révolutionnaire.

C'est particulièrement vrai d'abord de la figure de cet «impossible citoyen » qu'est l'étranger, étudiée par Sophie Wahnich en 1997 sous l'angle d'un conflit de droits (entre droit positif et droits naturels) ${ }^{78}$. Plus généralement, la question de l'intégration sous conditions, puis de l'exclusion sans réserve des étrangers de la communauté citoyenne, a permis d'approfondir la question de l'articulation entre citoyenneté et nationalité, successivement explorée en 2000 par Michael Rapport, en 2002 par François Weil et en 2004 par Peter Sahlins ${ }^{79}$. Enfin, dernièrement, c'est dans une perspective européenne, autour de l'articulation entre citoyenneté et territorialité, qu'a été reposée la question de la citoyenneté problématique de ces étrangers devenus citoyens malgré eux dans le cadre de l'expansion révolutionnaire et napoléonienne. Les premières études consacrées à ces "citoyens de l'étranger» a ainsi permis de réévaluer l'éventail "des citoyennetés européennes ", en fonction du plus ou moins grand degré de souveraineté reconnu aux territoires satellisés par la Grande Nation, puis par l'Empire - soit qu'ils bénéficient d'une " citoyenneté à la française » (dans le cadre des républiques-sœurs du Directoire), soit qu'ils bénéficient d'une "citoyenneté française" (dans le cadre des nouveaux départements annexés sous l'Empire) ${ }^{80}$. De ces « citoyens étrangers » à ces « Français de l'étranger ", c'est donc aujourd'hui toute la gamme et toutes les échelles de ces citoyennetés "greffées", en même temps que les Constitutions et le Code civil, qui mériteraient d'être encore davantage approfondies. 
31 Sur le combat mené dans les colonies françaises par les libres de couleur et les esclaves pour conquérir le statut de citoyen et les droits de citoyenneté, nous nous contenterons de renvoyer aux deux articles consacrés à cette question dans le présent numéro (voir Frédéric Régent et Yerri Urban). Nous n'examinerons pas non plus la question de la citoyenneté "paradoxale ${ }^{81}$ », du moins problématique, des femmes (analysée dans ce recueil par Guillaume Mazeau et Clyde Plumauzille), sinon pour souligner que, depuis le Bicentenaire, la question de leur exclusion de la citoyenneté ne va plus tant de soi ${ }^{82}$ puisqu'elle n'a cessé d'alimenter le débat historiographique - ce que révèle l'ampleur de la bibliographie qui leur est consacrée ${ }^{83}$ mais également le glissement qui s'opère depuis quelques années d'une histoire des femmes à une histoire du genre en Révolution ${ }^{84}$.

Ce glissement a permis de ne plus circonscrire la question de la citoyenneté des femmes à l'étude des différentes formes de leur participation politique et de leurs multiples manières d'investir l'espace public, par leurs prises d'armes ou leurs prises de paroles ${ }^{85}$. Dans le sillage des travaux pionniers de Lynn Hunt et Carla Hesse ${ }^{86}$, Suzanne Desan, Jennifer Heuer et Anne Verjus étudient en effet leur rôle décisif dans la réinvention d'une sphère domestique républicaine ${ }^{87}$ - dans laquelle l'épouse, la mère, la sœur, la fille se revendiquent et sont reconnues comme des citoyennes au sens où elles sont dépositaires des valeurs morales de la République. Ce faisant, il s'agit donc moins d'étudier leur combat militant en faveur de l'égalité citoyenne en vertu des principes du droit naturel que d'envisager leur citoyenneté à l'aune de leurs droits civils et de leurs devoirs maternels et matrimoniaux, qui font d'elles, malgré tout, des citoyennes.

C'est donc aujourd'hui autour de cet espace nodal de la famille qu'est revisitée la citoyenneté des femmes et des hommes ${ }^{88}$, ce qui amène à la fois à réinterroger la frontière poreuse entre la sphère privée (des individus) et la sphère publique (des citoyens), mais également à étudier la figure du citoyen dans sa dimension intime et morale - à travers notamment la catégorie de "bonnes mœurs ${ }^{89}$.» Ce faisant, l'historiographie tend insensiblement à glisser de l'étude de la citoyenneté à l'étude du civisme - autrement dit, de l'étude des droits à celle des devoirs du citoyen.

\section{De la citoyenneté au civisme : les recherches en cours sur la « morale citoyenne »}

En effet, parce que le mot «citoyen » se décline autant comme un terme qui envahit la langue politique, juridique et commune, que comme un «titre» dont on s'honore et se décore, mais que l'on peut aussi perdre, la citoyenneté est moins une évidence qu'une exigence. L'évidence des droits consacrés dans la Déclaration de 1789 s'articule en effet avec l'exigence des devoirs que la citoyenneté suppose. À ce titre, le citoyen est autant un être de devoirs qu'un sujet de droits - puisque même non " déclarés ", les devoirs civiques qui lui incombent sont le pendant des droits politiques qu'on lui accorde. Ces devoirs civiques se confondent en effet avec les critères qui conditionnent l'accès aux assemblées primaires et qui autorisent donc le citoyen à exercer ces droits politiques. Ce devoir est d'abord fiscal: le citoyen est contribuable puisqu'il doit participer à la prospérité nationale ; il est ensuite militaire : le citoyen est soldat puisqu'il participe au service de la garde nationale; le devoir est enfin politique et moral: le citoyen doit non seulement respecter et adhérer à la loi par la prestation du serment civique mais également par une conduite conforme à la «morale civique ». En ce sens, la citoyenneté ne se résume pas à un statut juridique ou à une pratique politique, elle se décline en termes de mérite 
individuel (les «talents») et de la dignité morale (les "vertus»). En envisageant le citoyen sous l'angle de ces devoirs, ce sont donc d'autres visages de la citoyenneté qui ont émergé au cœur des problématiques actuelles.

La renaissance de l'histoire du fait militaire sous la Révolution a ainsi permis de revisiter les multiples déclinaisons du citoyen-soldat: depuis celle du garde national jusqu'à celle $\mathrm{du}$ conscrit, en passant par celle du volontaire de 1791-1792 et du requis de l'an II ${ }^{90}$. Dans le sillage des travaux de Jean-Paul Bertaud ${ }^{91}$ et d'Alan Forrest ${ }^{92}$, les études de Roger Dupuy (sur la garde nationale) ${ }^{93}$ et de Thomas Hippler et Annie Crépin (sur la conscription) ${ }^{94}$ ont ainsi permis d'envisager l'armée révolutionnaire comme une véritable école de la citoyenneté, en examinant le processus concomitant de métamorphoses des soldats en citoyens et des citoyens en soldats. Ce faisant, ils ont permis d'interroger à nouveaux frais la frontière ténue entre la sphère civile et la sphère militaire et l'impact de leur interaction réciproque dans la définition du politique et la rupture entre Révolution et Empire.

Si la figure du citoyen contribuable n'a encore guère suscité d'études ${ }^{95}$, il faut cependant noter que c'est désormais autour du thème de la «citoyenneté capacitaire » que sont aujourd'hui repensées les dynamiques de la distinction sociale ${ }^{96}$ ainsi que les logiques de l'exclusion des non-contribuables, c'est-à-dire de tous ceux qui sont considérés comme passifs politiquement parce que dépendants socialement - qu'il s'agisse de ceux qui sont recensés comme «indigents» et de ceux qui sont disqualifiés comme «infirmes de la Raison ${ }^{97}$.»

En effet, si la citoyenneté suppose les «talents » nécessaires et la "raison » suffisante pour faire un bon usage de ses droits politiques, elle suppose aussi des " vertus ${ }^{98}$. " Ce sont en effet les «talents" et les "vertus " qui conditionnent l'accès aux fonctions publiques (dès 1789) et, plus largement, l'exercice des droits politiques de citoyen (à partir de 1795). Si les travaux relatifs à la question de l'instruction publique continuent à approfondir la question de la formation civique du citoyen ${ }^{99}$, ce sont aussi tous les processus de façonnement de la morale citoyenne qui constituent l'un des chantiers les plus prometteurs de ces dernières années. En effet, la question de l'éthique citoyenne ne se limite plus à son strict aspect pédagogique (les modalités de formation du citoyen vertueux), elle prend également en compte sa dimension judiciaire (les modalités de répression du citoyen indigne).

Il appartient à Anne Simonin, d'avoir replacé la question de «l'honneur» et de la "vertu» au cœur des réflexions sur la citoyenneté républicaine, en montrant que le statut de citoyen étant avant tout un titre de dignité. Dans son livre publié en 2008, Le Déshonneur dans la République ${ }^{100}$, elle propose en effet une analyse radicalement neuve des mécanismes de l'exclusion, qu'elle ne limite pas aux seules catégories ciblées par le droit constitutionnel, mais qu'elle étudie à travers le spectre large des conduites "indignes ", réprouvées par le code pénal et réprimées par la peine de "dégradation civique ». Ce qui est au cœur de ce livre, ce n'est donc pas tant la figure du "non-citoyen » (du citoyen exclu) à qui l'on refuse, par la loi constitutionnelle, le droit à la citoyenneté, que celle du «mauvais citoyen" (du citoyen indigne), à qui l'on ôte, par la loi pénale, ses droits de citoyen. Anne Simonin a ainsi démontré que la caractéristique du régime républicain consistait non pas tant à exclure définitivement ces citoyens indignes, qu'à les écarter temporairement, en les privant provisoirement de leurs droits. En inventant ainsi le principe de l'infamie de droit, la $1^{\text {ère }}$ République a cherché à bâtir la citoyenneté sur un véritable « code civique » dont le code pénal fut le premier gardien. 
Ce faisant, Anne Simonin a proposé une relecture radicalement neuve de la typologie des citoyennetés en Révolution. Cette typologie ne s'organise pas tant autour d'un critère social, qui opposerait une élite bourgeoise à une masse populaire autour de la logique hiérarchisée sous-tendue par la citoyenneté capacitaire. Elle ne s'organise pas tant non plus autour du critère juridique, c'est-à-dire autour de la logique binaire de l'exclusion, qui oppose, d'abord, les non-citoyens aux citoyens et, à une échelle plus fine, les citoyens «actifs» aux citoyens "passifs». Elle se structure aussi et surtout en fonction d'un critère judiciaire, c'est-à-dire autour de la logique graduelle de la dégradation civique, qui fait reposer les différents échelons de la citoyenneté sur les différents degrés de peines encourues par les « mauvais » types de citoyens (de l'inhabile à l'incivique en passant par l'indigne et l'infâme) ${ }^{101}$. "L'ordre civique » qu'invente la Révolution se structure ainsi désormais autour de l'étude de l'échelle des droits et des devoirs du citoyen.

De ce rapide survol historiographique, il faut donc conclure que si le spectre large des identités, des pratiques et des espaces de la citoyenneté a été entièrement revisité, ce sont aussi les frontières de la citoyenneté qui sont désormais repensées en termes dynamiques et dialectiques. Bien que l'étude de la citoyenneté ne se soit que tardivement imposée dans le champ des études révolutionnaire, elle est aujourd'hui explorée, à toutes les échelles, dans toutes ses figures et dans toutes ses gammes, comme le principal legs de la modernité politique qui s'invente sous la Révolution.

\section{NOTES}

1. Michel vovelLE, "L'historiographie de la Révolution française à la veille du bicentenaire ", AHRF, n² 272, 1988, p. 113-126 (p. 125-126). C'est nous qui soulignons.

2. Michel vovelle, Combats pour la Révolution française, Paris, SER, 2001, p.9. C'est nous qui soulignons.

3. Michel VOVELLE, art. cit., p. 118.

4. Antoine DE BAECQUE, «L'histoire de la Révolution française dans son moment herméneutique », dans Michel Vovelle (dir.), Recherches sur la Révolution. Un bilan des travaux scientifiques du bicentenaire, Paris, La Découverte, 1991, p. 11-23.

5. Michel VOVELLE (dir.), Recherches sur la Révolution. Un bilan des travaux scientifiques du bicentenaire , Paris, La Découverte, 1991; Michel vovelle (dir.), 1789-1799, Nouveaux chantiers d'histoire révolutionnaire. Les institutions et les hommes, Paris, CTHS, 1995. Voir les notes ci-dessous pour les autres références bibliographiques portant sur ces « bilans » et « chantiers » historiographiques. 6. Pour une reconstruction de ce "récit», voir Jean-Clément MARTIN, Nouvelle Histoire de la Révolution française, Paris, Perrin, 2012.

7. Gary KATEs (dir.), The French Revolution. Recent debates and New Controversies, Londres et NY, Routledge, 1998. Voir également le numéro spécial « The French Revolution Twenty Years later after the Bicentennial », French historical Studies, n 32 (4), 2009.

8. François FURET, Penser la Révolution française, Paris, Gallimard, 1978.

9. Michel vovelle, «A la résurrection des Piques », dans Michel BIARD (dir.), La Révolution française. Une histoire toujours vivante, Paris, Tallandier, 2010, p. 17-25 (p. 22). 
10. Martine LAPIED, Christine PEYRARD (dir.), La Révolution française au carrefour des recherches, Aixen-Provence, publication de l'Université d'Aix-en-Provence, 2002.

11. Jean-Clément MARTin (dir.), La Révolution à l'œuvre. Perspectives actuelles dans l'histoire de la Révolution française, Rennes, PUR, 2005.

12. Michel BIARD (dir.), La Révolution française. Une histoire toujours vivante, Paris, Tallandier, 2010.

13. Michel vovelle, « Historiographie de la Révolution (II) », AHRF, $\mathrm{n}^{\circ} 273,1988$, p. 307-315 : « Le cliché est cependant reçu et largement reproduit d'un déclin lié à l'absence de renouvellement, à la répétitivité, à la rigidité de schémas reproduits ne varietur » (p. 311).

14. Jean-Luc CHAPPEY, Bernard GAINOT, Guillaume MAZEAU, Frédéric RÉGENT, Pierre SERNA, Pour quoi faire la Révolution, Marseille, Agone, 2012.

15. Michel vovelle, « Du tout social au tout politique », AHRF, $\mathrm{n}^{\circ} 310,1997, \mathrm{p}$. 545-555.

16. Carla HESSE, «The New Jacobins », French historical Studies, $n^{\circ} 32$ (4), 2009, p. 664-670.

17. Alphonse AULARD, Histoire politique de la Révolution française, origines et développement de la Démocratie et de la République (1789-1804), Paris, Armand Colin, 1901. Cet ouvrage connaît six rééditions successives jusqu'en 1926 et plus aucune jusqu'en 1977.

18. Michel Vovelle (dir.), Les colloques du bicentenaire: répertoire des rencontres nationales et internationales, Paris, La Découverte, 1991, p. IV-VI et p. XXI ; Antoine DE BAECQUE, art. cit., p. 22 et note 76.

19. Roger CHARTIER, «Bicentenaire : un Bilan », Le Monde, 7 décembre 1989 : « C'est l'un des traits heureux des travaux récents, l'histoire de la Révolution n'est plus ce monde à part, refermé sur des questions spécifiques qu'elle a trop longtemps été, mais elle devient un moment privilégié où peut s'observer, dans la radicalité et dans l'urgence du bouleversement, la force perdurable des contraintes imposées et des dominations acceptées. "

20. Claude NICOLET, L'Idée républicaine en France. Essai d'histoire critique (1789-1924), Paris, Gallimard, 1982 ; John РосоК, Le moment machiavélien. La pensée politique florentine et la tradition républicaine atlantique, Paris, PUF, 1997 ; Eric Gojosso, Le concept de république en France (XVI ${ }^{e}$-XVIII ${ }^{e}$ siècle), Aixen-Provence, Presses universitaires d'Aix-en-Provence, 1998; Jean-Fabien SPITZ, Le moment républicain en France, Gallimard, 2005.

21. Michel vovelle (dir.), Révolution et République : l'exception française, Paris, éd. Kimé, 1994.

22. Annie JOURDAN, La Révolution, une exception française?, Paris, Flammarion, 2004.

23. Claude NICOLET, Michel vovelle (dir.), La République, l'Europe et l'universel, Belfort, I.R.E.P. Belfort, 1993 ; Robert CHAGNY (dir.), La Révolution française, idéaux, singularités, influences, Grenoble, Presses Universitaires de Grenoble, 2002 ; Pierre SERNA (dir.), Républiques-sœurs. Le Directoire et la Révolution atlantique, Rennes, PUR, 2009; Yannick BOSC, Rémi DALISSON, Jean-Yves FRÉTIGNÉ, Christopher HAMEL, Carine Lounissi, Culture des républicanismes, Paris, éd. Kimé, 2015.

24. «Révoltes et révolutions en Europe et aux Amériques (1773-1802) ».

25. Françoise BRUNEL, «L'histoire politique de la Révolution française : quelques réflexions sur l'historiographie récente", dans Martine Lapied et Christine Peyrard (dir.), op. cit., p. 115-125, note 27.

26. Sarah MAZA, The Myth of the French Bourgeoisie. An Essay on the Social Imaginary, 1750-1850, Cambridge, Harvard University Press, 2003 ; Jean-Pierre JESSENNE (dir.), Vers un ordre bourgeois? Révolution française et changement social, Rennes, PUR, 2007.

27. Philippe BOURDIN, Bernard GAINOT (dir.), La République directoriale, Clermont-Ferrand, SER et Université Blaise-Pascal, 1998, 2 vol.; Michel BIARD (dir.), Les politiques de la Terreur, 1793-1794, Rennes, PUR, 2008 ; Marc BELISSA, Yannick BOSC, Florence GAUTHIER (coord.), Républicanismes et droit naturel, des humanistes aux Révolutions des droits de l'homme et du citoyen, Paris, Kimé, 2009 ; Michel BIARD, Hervé LeUWERs (dir.), Visages de la Terreur. L'exception politique de l'an II, Paris, Armand Colin, 2014. 
28. Edgar QUINET, La Révolution, Paris, Lacroix, 1865.

29. Ran HALEVI, La monarchie républicaine. La Constitution de 1791, Paris, Fayard, 1996.

30. Pierre SERNA, «Comment meurt une monarchie? 1774-1792», dans Joël CORNETTE (dir.), La Monarchie entre Renaissance et Révolution, 1715-1792, Paris, Seuil, 2000, p. 425-511.

31. Roger Dupuy, Marcel morabito (dir.), 1795. Pour une République sans révolution, Rennes, PUR, 1996 ; Michel vovelle (dir.), Le Tournant de l'an III, Paris, CTHS, 1997 ; Jacques BERNET, Jean-Pierre JESSENNE et Hervé LEUWERS (dir.), Du Directoire au Consulat, Lille, Université de Valenciennes et CHRENO, 1999-2001, 3 vol. ; Michel BIARD, Philippe BOURDin, Hervé LEuWERS et Pierre SERNA (dir.), Entrer en République, Paris, Armand Colin, 2013.

32. Renée WALDINGER, Philip DAWSON et Isser WOLOCH (ed.), The French Revolution and the Meaning of Citizenship, Westport, Greenwood Press, 1993.

33. Claude FIEVET (dir.), Invention et réinvention de la citoyenneté, Paris, éd. Joëlle Sampy, 2000 ; Michel PERTUÉ (dir.), Suffrage, citoyenneté et révolutions. 1789-1848, Paris, SER, 2002; Raymonde MONNIER (dir.), Citoyens et citoyenneté sous la Révolution française, Paris, SER, 2006 ; Annie CRÉPIN, Jean-Pierre JESSENNE, Hervé LeUWERS (dir.), Civils, citoyens-soldats et militaires dans l'État-nation, 1789-1815, Paris, SER, 2006.

34. François FURET, Mona OZOUf (dir.), Dictionnaire critique de la Révolution française, Paris, Flammarion, 1988, 4 vol.; Albert sовоUl (dir.), Dictionnaire historique de la Révolution française, Paris, PUF, 1989.

35. Pour une remise en cause récente de la catégorie de "peuple ", voir Roger DUPUY, La politique du peuple. Racines, permanences et ambiguïté du populisme, Paris, Albin Michel, 2002 et Deborah COHEN, La nature du peuple : les formes de l'imaginaire social, XVIII ${ }^{e}-X X I^{e}$ siècles, Seyssel, Champ Vallon, 2010.

36. Pour n'en citer que quelques-unes: Christine LE BOZEC, Boissy d'Anglas, un grand notable libéral, Privas, Fédération des CEuvres Laïques de l'Ardèche, Imp. Lienhart, 1995 ; Hervé LEUwERS, Un juriste en politique. Merlin de Douai (1754-1838), Arras, Artois Presses Université, coll. Histoire, 1996 ; Pierre SERNA, Antonelle. Aristocrate révolutionnaire, 1747-1817, Paris, Éditions du Félin, 1997.

37. Jean-Pierre JESSENNE, «L'histoire sociale de la révolution française: entre doute et renouvellement ", dans Jean-Clément Martin (dir.), La Révolution à l'œuvre, op. cit., p. 23-35.

38. Voir notamment les différents volumes du Dictionnaire des usages socio-politiques du français (1770-1815) publiés entre 1985 et 2003 par l'équipe " $18^{\text {ème }}$ et Révolution » en 8 fascicules : 1. Désignants socio-politiques, Paris, Klincksieck, 1985 ; 2. Notions-concepts, Paris, Klincksieck, 1987 ; 3. Dictionnaires, normes, usages, Paris, Klincksieck, 1988; 4. Désignants socio-politiques, Paris, Klincksieck, 1990; 6. Notions pratiques, Paris, Klincksieck, 1989; 7. Notions théoriques, Paris, Champion, 2003 ; 8. Notions pratiques : patrie, patriotisme, Paris, Champion, 2006. Voir également Langages de la Révolution (1770-1815), actes du $4{ }^{\text {ème }}$ colloque international de lexicologie politique organisé par l'Equipe $18^{\text {ème }}$ et Révolution, Paris, Klincksiek, 1995 et Jacques Guilhaumou, Raymonde MONNIER (dir.), Des notions-concepts en révolution autour de la liberté politique à la fin du XVIII ${ }^{e}$ siècle, Paris, SER, 2003.

39. Jacques Gullhaumou, La langue politique et la Révolution française: de l'événement à la raison linguistique, Paris, Méridiens-Klincksieck, 1989; Hélène DUPUY, «Pour une redécouverte du politique à travers les notions-concepts", dans Michel Vovelle (dir.), Recherches sur la Révolution, op. cit., p. 70-78; Jacques GUILHAumou ; «De l'histoire des concepts à l'histoire linguistique des usages conceptuels ", Genèses, 38, 2000, p. 105-118; Jacques Gullhaumou, «La langue politique : des notions-concepts en usage ", dans Jean-Clément Martin (dir.), La Révolution à l'œuvre, op. cit., p. 125-138.

40. Sonia BRANCA-ROSOFF, «Les mots de parti pris : citoyen, aristocrate et insurrection dans quelques dictionnaires (1762-1798) », dans Dictionnaire des usages socio-politiques, t. 3, Saint-Cloud, INALF, 1988, p. 47-73 ; Annie GEFFROY, «Citoyen / Citoyenne (1753-1829)», dans Dictionnaire des usages 
socio-politiques 1770-1815, t. 4, op. cit., p. 63-86 ; Raymonde MONNIER, «Libres et égaux en droits ", dans Des mots en liberté. Mélanges Maurice Tournier, Saint-Cloud, ENS Editions, 1998, p. 277-284; Raymonde MONNIER, «Démocratie et Révolution française ", Mots. Les langages du politique, $\mathrm{n}^{\circ} 59$, 1999, p. 47-68 ; Raymonde MONNIER, « Démocratie représentative ou République démocratique? : de la querelle des mots (république) à la querelle des Anciens et des Modernes ", $A H R F, \mathrm{n}^{\circ} 3,2001$, p.1-21; Raymonde MONNIER, "Autour des usages d'un concept indistinct: peuple sous la Révolution française", Dix-Huitième Siècle, $n^{\circ} 34$, 2002, p. 391-420; Jacques Gullhaumou, Raymonde MONNIER, "Des notions en révolution : l'art social et la République », dans Martine Lapied et Christine Peyrard (dir.), op.cit., p. 235-248; Raymonde MONNIER, "Républicanisme, libéralisme et Révolution française ", dans Florence Gauthier, Jacques Guilhaumou (dir.), Les libéralismes au regard de l'Histoire, Actuel Marx, n³2, 2002, p. 83-108; Raymonde MONNIER, «Républicanisme et Révolution française », French Historical Studies, vol. 26-1, 2003, p. 87-118 ; Raymonde MONNIER, "Que signifie être républicain en septembre 1792 », dans Michel Biard, Philippe Bourdin, Hervé Leuwers, Pierre Serna (dir.), 1792. Entrer en République, op. cit., p. 37-49.

41. Quentin SKINNER, Les fondements de la pensée politique moderne, Paris, A. Michel, 2001.

42. Michel BORGETTO, Le droit non civil de la famille, PUF, 1983 ; Jean-Louis HALPÉRIN, L'impossible Code Civil, PUF, 1992 ; Pierre lascoumes, Pierrette POnCEla, Pierre LENoËL, Au nom de l'ordre. Une histoire politique du code pénal, Paris, Hachette, 1989.

43. Michel TROPER, La séparation des pouvoirs et l'histoire constitutionnelle française, Paris, Librairie générale de Droit et de Jurisprudence, 1973; Paolo colombo, Governo e costituzione: la trasformazione del regime politico nelle teorie dell'età rivoluzionaria francese, Milano, Giuffrè editore, 1993 ; Roberto MARTUCCI (dir.), Constitution et Révolution aux États-Unis d'Amérique et en Europe (1776-1815), Macerata, Laboratorio di Storia Costituzionale, 1995; Marcel MORABITo, Daniel BOURMAUD, Histoire constitutionnelle et politique de la France (1789-1848), Paris, Montchrestien, 1996 ; Jean BART (dir.), La Constitution du 24 juin 1793. L'utopie dans le droit français ?, Dijon, EUD, 1997 ; Michel TROPER, "La notion de citoyen sous la Révolution française ", dans Études en l'honneur de Georges Dupuis, Paris, LGDJ, 1997, p. 301-321 ; Michel TROPER, Terminer la Révolution. La constitution de 1795, Paris, Fayard, 2006 ; Guillaume GLÉNARD, L'exécutif et la constitution de 1791, Paris, PUF, 2010.

44. Suzanne DESAN, «What's after Political Culture? Recent French Revolutionary Historiography? ", French Historical Studies, n² 23 (1), 2000, p. 163-196.

45. Voir les travaux réalisés dans le cadre de la numérisation de la collection Baudoin par l'ANR Rev-Loi (2009-2013) URL : https://collection-baudouin.univ-paris1.fr ; Guillaume MAZEAU, Maria CASTELLÀ PUJOLS (dir.), «Les comités des Assemblées révolutionnaires : des laboratoires de la loi », La Révolution française, $\mathrm{n}^{\circ}$ 3, 2012 [en ligne], URL : http://lrf.revues.org/673 ; Anne SIMONIN, YannArzel DUREL-MARC (dir.), "Les sources matérielles de la loi sous la Révolution (1789-1795)», Clio@Themis, revue d'histoire du droit, nº, 2013 [en ligne], URL : http://www.cliothemis.com/ Clio-Themis-numero-6 ; le colloque La loi en Révolution (1789-1815). Fonder l'ordre et établir la norme, organisé les 12-14 septembre 2013 par Pierre Serna et Anne Simonin.

46. Patrick BRASART, Paroles de la Révolution. Les assemblées parlementaires (1789-1794), Paris, Minerve, 1988 ; André CASTALDO, Les méthodes de travail de la Constituante. Les techniques délibératives de l'Assemblée Nationale (1789-1791), Paris, PUF, 1989; Jean-Philippe HEURTIN, L'Espace public parlementaire. Essai sur les raisons du législateur, Paris, PUF, 1999.

47. Michel BIARD, Pierre SERNA (dir.), «Une révolution du pouvoir exécutif?", AHRF, n³32, $2003 / 2$.

48. Jacques MOREAU, Michel VERPEAUX (dir.), Révolution et décentralisation, le système administratif français et les principes révolutionnaires de 1789, Paris, Economica, 1992 ; Michel BIARD, Missionnaires de la République. Les représentants du peuple en mission (1793-1795), Paris, CTHS, 2002 ; Michel BIARD, Les Lilliputiens de la centralisation. Des intendants aux préfets, les hésitations d'un "modèle français ", 
Seyssel, Éditions Champ-Vallon, 2007; Gaïd ANDRO, Une génération au service de l'Etat. Les procureurs-généraux syndics de la Révolution française (1780-1830), Paris, SER, 2015.

49. Michel VOVELLE (dir.), La Révolution et l'ordre juridique privé : rationalité ou scandale?, Paris, PUF, 1988, 2 vol.; Jean-Jacques CLÈRE, Jean-Louis HALPÉRIN (dir.), Ordre et désordre dans le système napoléonien, Paris, éditions La Mémoire du droit, 2003 ; Marc BELISSA, Repenser l'ordre européen (1795-1802). De la société des rois aux droits des nations, Paris, éd. Kimé, 2006 ; Jean-Pierre JESSENNE (dir.), Vers un ordre bourgeois? Révolution française et changement social, Rennes, PUR, 2007; "Justice, nation et ordre public », AHRF, n 350, octobre-décembre 2007 ; Bernard GAINOT, Vincent DENIS (dir.), Un siècle d'ordre public: de 1789 à la Troisième République, Paris, SER, 2009 ; Jean-Luc CHAPPEY, Ordres et désordres biographiques. Dictionnaires, listes de noms et réputation, des Lumières à Wikipedia, Seyssel, Champ Vallon, 2013.

50. Isser woloch, The New Regime. Transformations of the French civic order (1789-1820), New York, Norton and company, 1994.

51. Malcolm CROOK, "La Révolution française : l'âge d'or des élections », dans Martine Lapied, Christine Peyrard (dir.), La Révolution française au carrefour des recherches, op. cit.. Pour compléter cette mise au point historiographique, voir également: Serge ABERDAM, «Interpréter les votes révolutionnaires. Divergences et convergences de l'historiographie », dans Monnier Raymonde (dir.), Citoyens et citoyenneté, op. cit., p. 153-166; Bernard GAINOT, "Théorie et pratique(s) de la représentation politique ", dans Jean-Clément Martin (dir.), La Révolution à l'œuvre. Perspectives actuelles dans l'histoire de la Révolution française, Rennes, PUR, 2005, p. 139-149.

52. Malcolm сRоок, «Voter en assemblée sous la Révolution : le citoyen dans l'espace électoral », dans Raymonde Monnier (dir.), Citoyens et citoyenneté sous la Révolution française, Paris, SER, 2006, p. 167-177.

53. François FURET, «La monarchie et le règlement électoral de 1789 », dans Keith Michael Baker (dir.), The Political Culture of the Old Regime, Oxford, Pergamon Press, 1987, p. 375.

54. Maurice AgUlhon, La République au village. Les populations du Var de la Révolution à la Seconde République, Paris, Plon, 1970 [rééd. 1979], p. 17, p. 289, p. 471.

55. Jean-René SURATTEAU, «Heurts et malheurs de la sociologie électorale sous la Révolution française », AESC, mai-juin 1968, p. 556-580.

56. Serge ABERDAM, «Interpréter les votes révolutionnaires. Divergences et convergences de l'historiographie", dans Raymonde Monnier (dir.), Citoyens et citoyenneté sous la Révolution française, op. cit., p. 153-166.

57. Robert R. PALMER, The Age of Democratic Revolution, Princeton, Princeton University Press, 1959.

58. Albert sовоUL, Les sans-culottes parisiens en l'an II. Mouvement populaire et gouvernement révolutionnaire (2 juin 1793-9 thermidor an II), Paris, Clavreuil, 1958.

59. Geneviève VERDO, "Pierre Rosanvallon, archéologue de la démocratie », Revue historique, n -623, 2002/3, p. 693-720.

60. Pierre RosanVAllon, Le Sacre du citoyen. Histoire du suffrage universel en France, Paris, Gallimard, 1992 ; Pierre RosanVAllon, Le Peuple introuvable. Histoire de la représentation démocratique en France, Paris, Gallimard, 1998 ; Pierre RoSANVALlon, La Démocratie inachevée. Histoire de la souveraineté du peuple en France, Paris, Gallimard, 2000.

61. Patrice GUENIFFEY, Le nombre et la raison, La Révolution française et les élections, Paris, EHESS, 1993. Si cette thèse a d'emblée fait polémique, c'est d'abord en raison du matériau archivistique utilisé, qui a été jugé trop limité (quantitativement) et trop orienté (qualitativement). Mais c'est aussi et surtout en raison du présupposé idéologique, hérité d'Augustin Cochin, qui la sous-tend et qui part du principe que ces élections ne reflèteraient pas les opinions majoritaires des masses puisqu'elles seraient à la fois peu significatives (en raison de taux de participation très faibles) et peu représentatives (en raison des multiples instrumentalisations et manipulations dont elles 
furent l'objet). Sur la critique de cet ouvrage, voir les compte rendus de Melvin EDELSTEIN, AHRF, $\mathrm{n}$ - 303, 1996, p. 161-164 et John HORNE, AHRF, nº 311, 1998, p. 89-109.

62. Pour Pierre Rosanvallon, le peuple-souverain qui s'érige en entité abstraite en 1789 (le peuple-nation) ne coïncide pas avec la réalité sociale dont il est censé être l'émanation et l'incarnation (le peuple-société).

63. Serge ABERDAM, Serge BIANCHI (dir.), Voter, élire pendant la Révolution française, 1789-1799, Paris, CTHS, 1999.

64. Sur la critique de la notion de «démocratie directe ", voir Claudine wolikow, «Démocratie directe ", dans Serge Aberdam, Serge Bianchi (dir.), Voter, élire pendant la Révolution française, op. cit., p. 462.

65. Claudine wolikow, «1789-an III : l'émergence de la démocratie représentative ", dans Roger Bourderon (dir.), L'an I et l'apprentissage de la démocratie, Saint-Denis, éd. PSD, 1995. Cette analyse a été confortée depuis par Raymonde MONNIER, "Démocratie et Révolution française ", Mots. Les langages du politique, $\mathrm{n}^{\circ} 59,1999$, p. 47-68 et par Bernard GAINOT, «La notion de démocratie représentative et son occultation, entre la fin de l'Ancien Régime et la Restauration (1787-1830) », The European Legacy, 1999, vol. 4, n 6, p. 84-91.

66. Bernard GAINOT, 1799, un nouveau jacobinisme? La démocratie représentative, une alternative à Brumaire, Paris, CTHS, 2001.

67. Cette notion de "démocratie délibérative " a constitué selon Serge Aberdam l'un des grands « chaînons manquants » de l'histoire politique. C'est ce chaînon manquant qui aurait empêché de penser de façon dialectique l'opposition trop rigide à son sens entre les deux niveaux de pratiques démocratiques : celui de la démocratie électorale (démocratie représentative) et celui de la démocratie militante (démocratie directe), en ne prenant pas suffisamment en compte les phénomènes de circulations et de porosités entre les différents types d'assemblées de citoyens, officiellement convoquées par le pouvoir dans le cadre des assemblées primaires ou spontanément mises en œuvre par les citoyens dans le cadre des assemblées sectionnaires ou populaires.

68. Parmi ses nombreux articles, voir : Serge ABERDAM, «Délibérations en assemblées de citoyens et portions de souveraineté en 1793 », dans Michel Pertué (dir.), Suffrage, citoyenneté et révolutions, op. cit., p. 9-32 ; Serge ABERDAM, «Un aspect du référendum de 1793 : les envoyés du souverain face aux représentants du peuple», dans Michel Vovelle (dir.), Révolution et République, op. cit., p. 213-225; Serge ABERDAM, "L'élargissement du droit de vote de 1792 à 1793 ", dans Roger Bourderon (dir.), L'an I et l'apprentissage de la démocratie, op. cit., p. 255-270 ; Serge ABERDAM, « Une Constitution destinée à recevoir une sanction populaire ? Le sens d'une décision de principe ", dans Michel Biard, Philippe Bourdin, Hervé Leuwers, Pierre SERNA (dir.), 1792. Entrer en République, op. cit., p. 201-216.

69. Philippe TANCHOUX, Les procédures électorales en France de la fin de l'Ancien régime à la Première guerre mondiale, Paris, CTHS, 2004.

70. Malcolm своок, Elections in the French Revolution: an Apprenticeship in Democracy, 1789-1799, Cambridge, Cambridge University Press, 1996. Parmi ses principaux articles: Malcolm CROOK, "Aux urnes, citoyens! Urban and Rural Electoral Behavior during the French Revolution », dans Alan Forrest, Peter Jones (dir.), Reshaping France : town, country and region during French Revolution, Manchester, Manchester University Press, 1991, p. 152-167; Malcolm CROOK, «Les Français devant le vote: participation et pratique électorales à l'époque de la Révolution ", dans Les pratiques politiques en province à l'époque de la Révolution française, Montpellier, université Paul Valéry, 1988, p. 27-37 ; Malcolm CROOK, «Le candidat imaginaire, ou l'offre et le choix dans les élections de la Révolution française », AHRF, n³21, 2000, p. 91-100; Malcolm CROOK, "Voter en assemblée sous la Révolution : le citoyen dans l'espace électoral », dans Raymonde Monnier (dir.), Citoyens et citoyenneté, op. cit., p. 167-177; Malcolm сROоK, « The Uses of Democracy. Elections and 
Plebiscites in Napoleonic France ", dans Maire F. Cross, David Williams (dir.), The French Experience from Republic to Monarchy (1792-1824): New Dawns in Politics Knowledge and Culture, Basingstoke, Palgrave, 2000, p. 58-71.

71. Parmi ses principaux articles: Melvin EDELSTEIN, «Vers une sociologie électorale de la Révolution française: citadins et campagnards (1789-1793)», RHMC, 1975, n²2, p. 526-527; Melvin EDELSTEIN, « L'apprentissage de la citoyenneté : participation électorale des campagnards et des citadins (1789-1793) ", dans Michel Vovelle (dir.), L'image de la Révolution, Paris, Pergamon Press, 1989, 4 vol. , t. 1, p. 15-25 ; Melvin EDELSTEIN, « La place de la Révolution française dans la politisation des paysans ", AHRF, $\mathrm{n}^{\circ} 280,1991$, p. 131-149; Melvin EDELSTEIN, « Le comportement électoral sous la monarchie constitutionnelle (1790-1791) : une interprétation communautaire », AHRF, n 301, 1995, p. 361-398; Melvin EDELSTEIN, « La culture électorale française de l'époque révolutionnaire à l'époque napoléonienne ", dans Michel Biard, Annie Crépin, Bernard Gainot (dir.), La plume et le sabre: volume d'hommages offerts à Jean-Paul Bertaud, Paris, Publications de la Sorbonne, 2002, p. 489-497; "La participation électorale des Français (1789-1870) », RHMC, n -40-44, 1993, p. 629-642.

72. Melvin EDELSTEIN, La Révolution française et la naissance de la démocratie électorale, Rennes, PUR, 2014.

73. Ibid., p. 30-32.

74. Eugen WEBER, Peasants into Frenchmen: The Modernization of Rural France, 1870-1914, Stanford, Stanford University Press, 1976.

75. Maurice AGULHON, «Le suffrage universel et la politisation des campagnes françaises ", dans Maurice Agulhon, Histoire vagabonde, Paris, Gallimard, 1996, t. 3, p. 61-82.

76. Julien BOUCHET, Côme SIMIEN (dir.), Les passeurs d'idées politiques nouvelles au village, de la Révolution aux années 1930, Paris, SER, 2015.

77. Elizabeth F. COHEN, Semi-Citizenship in Democratic Politics, Cambridge, Cambridge University Press, 2009.

78. Sophie WAHNICH, L'impossible citoyen. L'étranger dans le discours de la Révolution française, Paris, Albin Michel, 1997.

79. Michael RAPPORT, Nationality and Citizenship in Revolutionary France. The Treatment of Foreigners (1789-1799), Oxford, Clarendon Press, 2000 ; Patrick weIL, Qu'est-ce qu'un Français? Histoire de la nationalité française depuis la Révolution, Paris, Grasset, 2002 ; Peter SAHLINS, Unnaturally French. Foreign citizens in the Old Regime and After, London, Cornell University Press, 2004.

80. L'idée de nation et l'idée de citoyenneté en France et dans les pays de langue allemande sous la Révolution, Belfort, IREP, 1989 ; Marc BELISSA, Fraternité universelle et intérêt national (1713-1795). Les cosmopolitiques du droit des gens, Paris, éd. Kimé, 1998 ; Sophie WAHNICH, « Les républiques-sœurs, débat théorique et réalité historique, conquêtes et reconquêtes d'identités républicaines ", AHRF, 1994/2, p. 165-177 ; François ANTOINE, Jean-Pierre JESSENNE, Annie JOURDAN, Hervé LEUWERS (dir.), L'Empire napoléonien. Une expérience européenne? ? Paris, Armand Colin, 2014.

81. Joan W. scotT, La citoyenne paradoxale. Les féministes françaises et les droits de l'homme, Paris, Albin Michel, 1988.

82. Geneviève FRAISSE, Muse de la raison. La démocratie exclusive et la différence des sexes, Aix-enProvence, Alinéa, 1989 ; Michèle RIOT-SARCEY, « XIX siècle : femmes ou l'impossible citoyenneté ", dans Roger Bourderon (dir.), L'an I et l'apprentissage de la démocratie, op. cit., 1995, p. 625-634; Evelyne MORIN-ROTUREAU (dir.), 1789-1799, combats de femmes: les révolutionnaires excluent les citoyennes, Paris, Autrement, 2003 ; SLEDZIEWSKI Elisabeth, "L'exclusion prononcée contre les femmes: pourquoi ?», dans Raymonde Monnier (dir.), Citoyens et citoyenneté, op. cit., 2006, p. 191-198.

83. Voir la partie VII. de la bibliographie d'Historiens-Géographes « Femmes et Citoyenneté ». 
84. Martine Lapied, «Histoire du Genre en Révolution », dans Jean-Clément Martin (dir.), La Révolution à l'œuvre, op. cit., p. 77-87; Dominique Godineau, Lynn Hunt, Jean-Clément Martin, Anne Verjus et Martine Lapied, « Femmes, genre, révolution », AHRF, no358, 2009, p. 143-166.

85. «La prise de parole publique des femmes », AHRF, $\mathrm{n}^{\circ}$ 344, avril-juin 2006.

86. Lynn HUNT, Le roman familial de la Révolution française, Paris, Albin Michel, 1995 ; Carla HESSE, The Other Enlightenment. How French Women Became Modern, Princeton, Princeton University Press, 2001.

87. Jennifer HEUER, Anne VERJUS, «L'invention de la sphère domestique au sortir de la Révolution ", AHRF, $\mathrm{n}^{\circ}$ 327, 2002/1, p. 1-28.

88. Anne VERJUS, Le cens de la famille. Les femmes et le vote, 1789-1848, Paris, Belin, 2002 ; Suzanne DESAN, The family on Trial in Revolutionary France, Berkeley, University of California Press, 2004 ; Philippe DAUMAS, Famille en Révolution, vie et relations familiales en Ile de France changements et continuités (1775-1825), Rennes, PUR, 2005 ; Jennifer HEUER, The Family and the Nation. Gender and Citizenship in Revolutionary France, 1789-1830, Londres, Cornell University Press, 2005 ; Anne VERJUS, Le bon mari. Une histoire politique des hommes et des femmes à l'époque révolutionnaire, Paris, Fayard, 2010.

89. Anne Simonin, «L'indignité contre les bonnes mœurs républicaines », dans Robert Belot (dir.), Tous Républicains! Origine et modernité des valeurs républicaines, Paris, Armand Colin, 2011, p. 213-231; Clyde Plumauzille, « Du 'scandale de la prostitution' à l'atteinte contre les bonnes mœurs. Contrôle policier et administration des filles publiques sous la Révolution française », Politix, 2014, 27, n 107, p. 9-31.

90. Annie CRÉPIN, Jean-Pierre JESSENNE, Hervé LEUWERS (dir.), Civils, citoyens-soldats et militaires dans l'État-nation, 1789-1815, Paris, SER, 2006 ; Alan ForRest, Karen HAGEMANN, Jane RENDALL (dir.), Soldiers, citizens and civilians : experiences and perceptions of the revolutionary and Napoleonic wars, 1790-1820, Basingstoke, Palgrave Macmillan, 2009.

91. Jean-Paul BERTAUd, La Révolution armée, les soldats-citoyens et la Révolution française, Paris, Robert Laffont, 1979.

92. Alan FORREST, Déserteurs et insoumis sous la Révolution et l'Empire, Paris, Perrin, 1988; Alan FORREST, The Soldiers of the French Revolution, London, Duke University Press, 1990.

93. Serge BIANCHI, Roger DUPUY (dir.), La Garde nationale entre nation et peuple en armes. Mythes et réalités, 1789-1871, Rennes, PUR, 2006 ; Roger DUPUY, La garde nationale (1789-1792), Paris, Gallimard, Folio Histoire, 2010.

94. Annie CRÉPIN, La conscription en débat ou Le triple apprentissage de la nation, de la citoyenneté, de la République: 1798-1889, Arras, Artois presses université, 1998 ; Annie CRÉPIN, Défendre la France. Les Français, la guerre et le service militaire, de la guerre de Sept Ans à Verdun, Rennes, PUR, 2005 ; Thomas HIPPLER, Soldats et citoyens. Naissance du service militaire en France et en Prusse, Paris, PUF, 2006.

95. Citons cependant les travaux de Nicolas Delalande sur le «civisme fiscal » et notamment Nicolas DELALANDE, Histoire sociale de l'impôt, Paris, La Découverte, 2010.

96. Jean-Luc CHAPPEY, « Raison et citoyenneté : les fondements culturels d'une distinction sociale et politique sous le Directoire», dans Raymonde Monnier (dir.), Citoyen et citoyenneté, op. cit., p. 279-288.

97. Voir à ce sujet le séminaire organisé entre 2010 et 2013 «Affreux, sales et méchants : les chiens de la République » au sein de l'IHRF par Pierre SERNA et Jean-Luc CHAPPEY [programme en ligne], URL : https://ihrf.univ-paris1.fr/enseignement/seminaires-et-cours/seminairepasses/2010-2013-affreux-sales-et-mechants/.

98. Charles WALton, La liberté d'expression en Révolution. Les mœurs, l'honneur, la calomnie, Rennes, PUR, 2014 ; Michel BIARD, Philippe BOURDIN, Hervé LEUWERS, Alain TOURRET, Vertu et politique. Les pratiques des législateurs (1789-2014), Rennes, PUR, 2015. 
99. Caroline fayolle, Jean-Charles BUtTIER (dir.), «Pédagogies, utopies et révolutions (1789-1848) », La Révolution française [revue en ligne], n 4, 2013, URL : http://lrf.revues.org/791.

100. Anne Simonin, Le Déshonneur dans la République. Une histoire de l'indignité (1791-1958), Paris, Grasset, 2008.

101. Anne SIMONIN, «Etre non-citoyen sous la Révolution française. Comment un sujet de droit perd ses droits », dans Raymonde Monnier (dir.), Citoyens et citoyenneté, op. cit., p. 289-305.

\section{RÉSUMÉS}

Cet article s'emploie à brosser un bilan des travaux consacrés à l'étude de la citoyenneté, en mettant d'abord en évidence les raisons d'une éclipse historiographique durable, avant d'envisager les raisons de sa réactualisation depuis les années 1990, à partir de chantiers connexes (élections, «marges » citoyennes et civisme). Ce faisant, il s'agit autant de s'interroger sur les multiples déclinaisons de la figure plurielle du citoyen que sur les frontières mouvantes de la citoyenneté révolutionnaire, qui apparaît finalement moins comme un objet classique que comme un «sujet neuf».

This article assesses work on citizenship, considering first the reasons for its enduring disappearance from the historiography, then the reasons for its renewal since the 1990s, within a connected set of literatures (elections, "margins" of citizenship and civicism). The task is as much to examine the multiple forms of the citizen as the moving boundaries of revolutionary citizenship, which appears ultimately to be a classic subject rather than a "new topic."

\section{INDEX}

Mots-clés : citoyenneté, historiographie, République, peuple, démocratie représentative, élections, étrangers, femmes, civisme, garde national, dégradation civique

Keywords : citizenship, historiography, Republic, people, representative democracy, elections, foreigners, women, civicism, national guard, civil degradation/loss of civil rights

\section{AUTEUR}

\section{VIRGINIE MARTIN}

Maitre de conférences à l'Université Paris 1 Panthéon-Sorbonne IHRF-IHMC (UMR 8066) 